\title{
CLOSURE OF OROANTRAL FISTULA WITH PEDICLED BUCCAL FAT PAD AND BUCCAL ADVANCEMENT FLAP
}

\author{
Namish Batra ${ }^{1}$, Renu Batra ${ }^{2}$
}

\section{HOW TO CITE THIS ARTICLE:}

Namish Batra, Renu Batra. "Closure of Oroantral Fistula with Pedicled Buccal Fat Pad and Buccal Advancement Flap". Journal of Evolution of Medical and Dental Sciences 2014; Vol. 3, Issue 29, July 21; Page: 8248-8250, DOI: $10.14260 /$ jemds/2014/3038

\begin{abstract}
Oroantral fistula is a pathological communication between oral cavity and maxillary sinus. There are many treatment modalities of closure of oroantral fistula and communication. We found double layer closure using buccal fat pad (BFP) and buccal advancement flap as most effective technique in large defects. Since the procedure was first described by Egyedi and has been reported in literature thereafter. In this article we present a case report of a 37 year old male patient who was suffering from oroantral fistula and was managed by double layer closure using BFP and buccal advancement flap.
\end{abstract}

KEYWORDS: Buccal Fat Pad, Oroantral Fistula and Buccal Advancement Flap.

INTRODUCTION: Any oroantral communication bigger than three mm left untreated or undiagnosed can lead to formation of oroantral fistula. Oroantral fistula is a pathological lining connecting oral cavity to maxillary sinus. Maxillary sinusitis, foul smell, nasal regurgitation, difficulty in having food and beverages are the common complication that patient faces. There are many flaps referred in literature for management of oroantral fistula like buccal advancement flap, palatal flap, tongue flap, buccal fat pad.

In this case report we have used double layer closure using BFP and buccal advancement flap. Buccal fat pad has four extensions buccal, pterygoid, superficial and deep temporal. All extensions are within a capsule. BFP can also be used in many other surgical reconstruction and rehabilitation procedures such as fistulas and oroantralcommunications ${ }^{1}$; in reconstruction after tumor.

Resection $^{2}$ in aesthetic corrections of the face; and in implant-graft coating ${ }^{3}$ Oral defect closure using the buccal fat pad has been employed because it is less time consuming, relatively easy to perform and has a high success rate. ${ }^{4}$

CASE REPORT: A 37 year old male Hindu patient presented with a chief complaint of acute sinusitis and nasal regurgitation from left nostril, a month after complicated extraction of 26. Clinical evaluation revealed the presence of oroantral fistula of $10 \times 6 \mathrm{~mm}^{2}$. Patient underwent panoramic radiographic examination and was prescribed oral antibiotics (Tab Amoxicillin 500mg TDS). Once the acute phase subsided, the patient was taken for primary repair under local anesthesia.

Surgical Technique: Under local anesthesia with vasoconstrictor, incision was made with two releasing incision and a circular incision around the oroantral fistula on buccal aspect. A full thickness mucoperiosteal Trapezoidal flap was raised from lateral surface of maxilla and infected epithelial lining was removed. (Figure 1). The Buccal Fat Pad (BFP) was exposed through a horizontal incision posterior to zygomatic buttress through the reflected flap. 
Blunt dissection was carried out and BFP was mobilized and carefully extended to recipient site (Figure 2). BFP was sutured to the palatal mucosa using 4-0 vicryl. Later incision was made in the periosteal layer of buccal trapezoidal flap (modified Von Rehrmann- flap) and was advanced over the BFP and sutured to palatal mucosa (Figure 3). Double layer closure was achieved.

Postoperatively, patient was given antibiotics, analgesic and nasal decongestants (Tab Amoxicillin 500mg TDS, Tab Paracetamol 650mg TDS and Xylometazoline $\mathrm{HCl}$ 0.1\%) and was advised not to blow his nose. The patient was kept under follow up till 3 months at regular intervals.

DISCUSSION: Oroantral communication and fistula are the complication of exodontia. In literature many surgical flaps were mentioned for closure of oroantral fistula. Buccal fat pad with skin graft was first used by Egyedi in closure of maxillary defects. ${ }^{5}$ It is located between the buccinator muscle medially, the anterior margin of the masseter muscle and the mandibular ramus and zygomatic arch laterally.4, 6 We had used BFP and buccal advancement flap due to ease of procedure, less time consumption and good prognosis with minimum morbidity of donor site.

Epithelization of flap occurs normally in 4 weeks. ${ }^{7,8}$ Covering BFP with buccal advancement flap enhances healing by minimizing chances of infection and failure of flap. BFP can be used alone also for closure of oroantral fistula, it has advantage that it does not alter the vestibular depth but in large defects there are chances of failure due to tension and insufficient volume. It has high chance of failure in smokers as well. Problems that can be noted while harvesting BFP ranges from perforation to shrinkage of BFP. 9 Double layer closure using BFP and buccal advancement flap gives more accurate results than BFP alone in such cases.

CONCLUSION: In large defects BFP along with buccal advancement flap gives good prognosis with minimum morbidity of donor site.

\section{REFERENCES:}

1. Hanazawa Y, Itoh K, Mabashi T, Sato K. Closure of oroantral communications using a pedicled buccal fat pad graft. J Oral Maxillofac Surg 1995; 53: 771-5.

2. Tideman H, Bosanquet A, Scott J. Use of the buccal fat pad as a pedicled graft. J Oral Maxillofac Surg 1986; 44: 435-40.

3. Dean A, Alamillos F, Garcia-López A, Sanches J, Penãlba M. The buccal fat pad flap in oral reconstruction. Head Neck 2001; 23: 383-8.

4. Martín-Granizo R, Naval L, Costas A, Goizueta C, Rodriguez F, Monje F, Muñoz M, Diaz F. Use of buccal fat pad to repair intraoral defects: review of 30 cases. Br J Oral Maxillofac Surg 1997; 35: 81-4.

5. Egyedi P. Utilization of the buccal fat pad for closure of oroantral and/ or oronasal communication. J Maxillofac Surg 1977 5(6) 241-247.

6. Liversedge RL, Wong K. Use of the buccal fat pad in maxillary and sinus grafting of the severely atrophic maxilla preparatory to implant reconstruction of the partially or completely edentulous patients: Technical note. Int J Oral Maxillofac Implants 2002; 17: 424- 428.

7. Samman N, Cheung LK, Tideman $H$. The buccal fat pad in oral reconstruction. Int J Oral Maxillofac Surg 1993; 22: 2-6. 5. 


\section{CASE REPORT}

8. Baumann A, Ewers R. Application of the buccal fat pad in oral reconstruction. J Oral Maxillofac Surg 2000; 58: 389-392.

9. Ramesh Candamourty, Manoj Kumar Jain, K. Sankar, M. R. Ramesh Babu. Double-layered closure of oroantral fistula using buccal fat pad and buccal advancement flap. J Nat Sci Biol Med. 2012 Jul-Dec; 3 (2): 203-205.

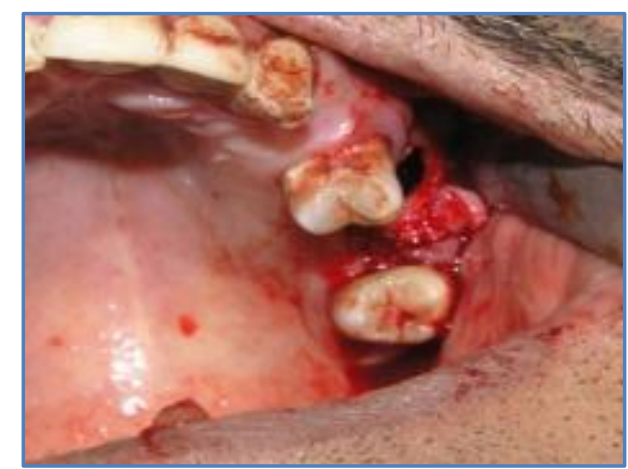

Fig. 1: Incision and flap reflection

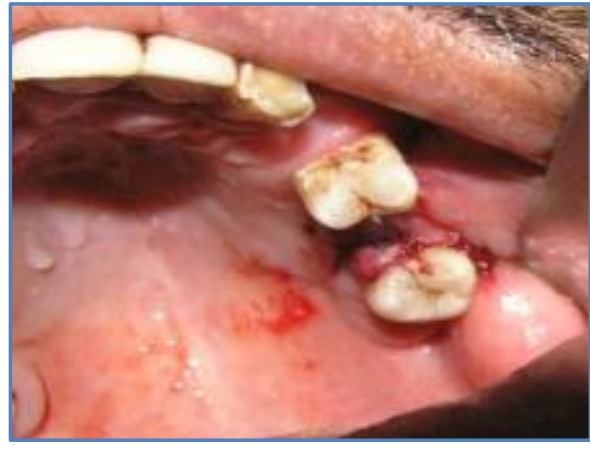

Fig. 3: Closure with buccal advancement flap

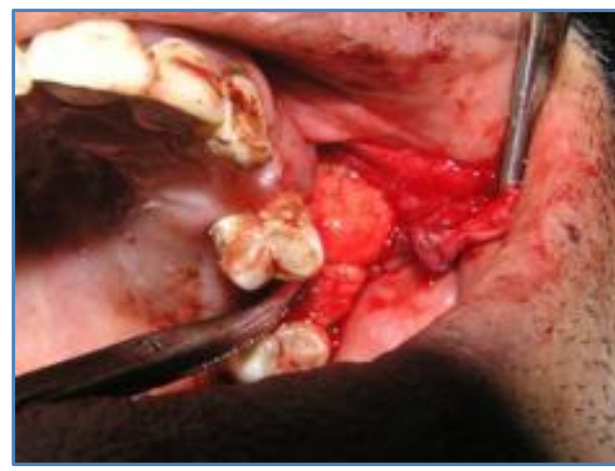

Fig. 2: Interpositioning BFP

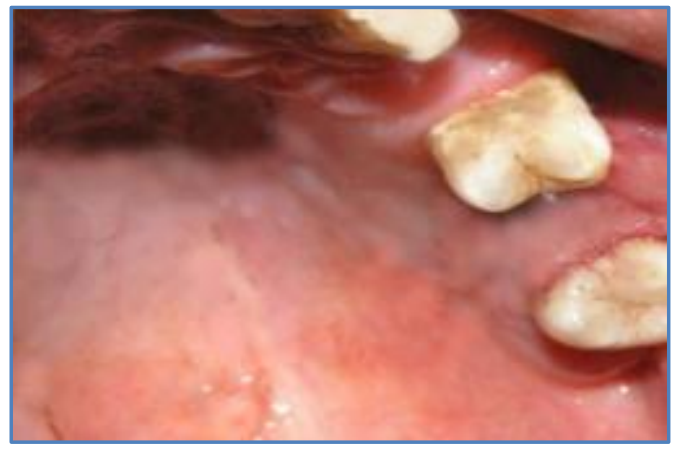

Fig. 4: Post-operative

\section{AUTHORS:}

1. Namish Batra

2. Renu Batra

\section{PARTICULARS OF CONTRIBUTORS:}

1. Senior Lecturer, Department of Oral \& Maxillofacial Surgery, Manubhai Patel Dental College and Hospital. Munjmahuda, Vadodara, Gujarat.

2. Senior Lecturer, Department of Conservative Dentistry \& Endodontics, Manubhai Patel Dental College and Hospital, Munjmahuda, Vadodara, Gujarat.

\section{NAME ADDRESS EMAIL ID OF THE CORRESPONDING AUTHOR:}

Dr. Namish Batra, C01, Akshara House, M. P. Dental College Campus, Munjmahuda, Vododara-390011, Gujarat. Email:drnamish_mds@yahoo.com

Date of Submission: 05/07/2014. Date of Peer Review: 06/07/2014. Date of Acceptance: 12/07/2014. Date of Publishing: 21/07/2014. 